\title{
Community-university partnership to enhance wellbeing of families: factors that sustain it
}

Nicolette V. Roman, Carol Rondganger and Jose Frantz

\begin{abstract}
Universities have a civic responsibility to engage with communities to capacitate and develop for the purpose of health and wellbeing. Although service learning serves part of this purpose, there is an additional requirement which is beyond just service learning. The requirement is a partnership between universities and communities which promotes culture, values, human rights and ethics. This paper provides a brief overview of the partnership and highlights the role of both universities and communities in the partnership as well as the potential factors that could hinder or enhance the sustainability of the partnership regardless of the context.
\end{abstract}

\section{Introduction}

Universities, as part of a higher education system, are sites of learning, creators and developers of knowledge, conductors of research and platforms for engagement (United Nations Educational, Scientific and Cultural Organization (UNESCO), 1998). These aspects of universities are explored in the UNESCO summary report of the World Declaration on Higher Education, which states that these "core missions" should "contribute to the sustainable development and improvement of society as a whole" (UNESCO, 1998:2). Ultimately, as training sites, the products of higher education should be graduates who are "highly qualified" and "responsible citizens" but, equally important, the higher education system should encourage continuous education, capacity development and accountability to society. This would mean that universities cannot be islands with the sole purpose of educating and developing students. Universities should then serve and engage the society they are responsible to. This society is the whole which represents communities containing families with students who may enter and exit the higher education system.

Over time, the World Declaration has been implemented, and universities that engage with communities have been referred to as "engaged universities". Preece (2013) observes that universities not only provide service learning to communities but also engage with those communities. This author suggests that the purpose of engaging with communities should be to find solutions to the challenges in communities and societies at large. In order to do this, Preece (2013) proposes that universities should partner with communities and that the 
partnership should be one that is beneficial to both parties, which is enshrined in the promotion of culture, values, human rights and ethics. Ultimately, when there is a partnership with communities, the intention should be one to build and strengthen for the well-being of communities (Loza, 2004) and to respond to the needs of a community (Kindred and Petrescu, 2015).

Although universities are mandated to develop these partnerships, a clear understanding of the development and sustainability of the partnership may not necessarily exist. Furthermore, communities have different contexts and, therefore, each partnership may be different, in spite of similarities. This means that there are potential complexities surrounding and within the partnership which need to be understood. The purpose of this review is threefold, in that it aims to: (1) explore the concept of community engagement, (2) understand the role of universities in partnerships, and (3) identify the factors that enable and sustain the partnership regardless of the context.

\section{Community engagement as an action}

There are various differing perspectives on how to define and describe the concept of community. Within communities themselves, a shared definition is often a challenge as the complexities of geography, history, culture and other social relationships which form part of the concept (Schenck, Nel and Louw, 2010; Kirmayer, Sehdev, Whitley, Dandeneau, and Isaac, 2009). This is also what makes the definition and description of community unique to a particular community rather than from a generalist perspective. Schenck et al. (2010) provide different perspectives on understanding communities in South Africa, highlighting particular aspects which need to be considered. First, when working with communities, there should be an awareness of identity, the notion of "communities of identity," characterised by a sense of identity and emotional connection to other members, shared norms and values and commitment to meeting common needs (Steuart, 1993). This is important when attempting to change behaviour. Second, communities have assets synonymous with strengths which could be located in the church, schools, families and so on. These assets could be described as the hooks which sustain a sense of relatedness in communities. A third aspect to consider is the role of "fundamental human needs" as identified by Max-Neef (1989). In applying this to communities, the notion is to consider that within communities, there are people or families with needs and challenges. It is these aspects which make it a complex process to find solutions that can be strengthened and enhanced. Schenck et al. (2010:9) suggest that in considering this third aspect, fundamental human needs, the term community should be treated as a "verb rather than a noun" because it is the people or families within communities who provide the authenticity of their experiences in their lived communities. This could mean, then, that in trying to find solutions to strengthen families and communities, an interdisciplinary perspective is provided and implemented (Preece, 2013).

If communities were to be approached from a perspective of being active rather than passive, it would mean that the point of departure should be that of engagement. What do we understand by engagement? The term could be described as interactions, exchanges or 
relations between different people on different aspects such as communication. These engagements could take the form of educating, informing, consulting, communicating, partnering or participating. Community engagement would, therefore, refer to the processes and practices involved in strengthening, building and healing particular groups of people or families in communities, who have a particular problem which requires more than an individual or singular approach (O’Mara-Eves, Brunton, McDaid, Oliver, Kavanagh, Jamal, Matosevic and Harden, 2013). In addition, the South African Higher Education Quality Committee (HEQC, 2004) describes community engagement as initiatives and processes through which the expertise of the higher education institutions in the areas of teaching, learning and research are applied to address issues relevant to their communities.

Wilcox (1994) identified five levels of community engagement. These levels represent a ladder which leads from mere consultation to complete engagement. The first level entails providing the community with information regarding what is planned. At this level, the community simply receives knowledge and this form of interaction can be seen as a monologue. At the second level, consultation affords the community an opportunity to provide feedback and engage with the organisers. Although interaction is present, the community is restricted as they are not allowed to propose any new ideas. At level three, the parties involved jointly decide, as joint decision-making is key to the interaction. Issues and concerns are discussed between both parties and possibly resolved. At this stage, the organisers are open to ideas and options put forward by the community. Acting together is the principle of level four which refers to the collaboration on all decisions made. These decisions are then carried out in partnership. The last level involves supporting independent community interests. Funds, advice, and other support are offered to assist the community with developing their own agendas. At this point, the parties maintain an equal relationship which is the desired outcome of this model (Wilcox, 1994). This ladder indicates a gradual move from what was seen as a one-way dialogue to complete engagement as partners. automatic process but with sufficient effort from both parties, it can grow to a mutual partnership which benefits all involved.

Similarly, O'Mara-Eves et al. (2013:44) explain the concept of community engagement as "approaches to involve communities in decisions that affect them". As with the term engagement, community engagement also takes on different shapes and forms of interactions and exchanges. There is the acknowledgement that a single definition of community engagement may be too restrictive and limiting as the contexts and challenges may differ across communities and would, therefore, require different sets of practices and processes (Bryan, 2009). Regardless, in order for community engagement to take effect, roles and responsibilities should be clarified.

\section{Roles and responsibilities of partners}

The notion of engagement involves partnering or partnership for the purpose of sharing, reciprocity and building capacity. Furthermore, the notion of partnering means that there is more than one person involved and that it could take different forms. For example, the partnership could be a dyadic system (meaning two parties in a partnership) which 
would be government and a community, business and a community or a university and a community. These dyadic systems assist in building communities in different ways. In the government-community partnership, government could support the partnership by means of improving service delivery and infrastructure in the community. In addition, government could provide funding to community-based organisations to provide training in improving or increasing knowledge and information on a particular aspect. However, as important as these activities may be, policy creation, revision and implementation by government are just as relevant and crucial because policy becomes the framework within which community development and growth could occur.

In the case of the business-community partnership, Loza (2004) highlights the role of business in its responsibility to society. The social responsibility ultimately aids in the wellbeing of communities and an increase in social capital. However, she believes that the partnership between business and community should move beyond social responsibility which often is a once-off type of involvement to communities. This means that the partnership should be more long-term and meaningful with the success of the partnership "based on collaboration in which both parties combine and exchange resources, talents and skills to develop innovative solutions to local and regional community problems in order to strengthen the capacity of the communities in which both sector serve and operate in" (Loza, 2004:300). For businesses this partnership encourages trust and minimises business risk, while enhancing relationships, creative business opportunities and the brand of the business. For communities, a long-term business-community partnership benefits the community by businesses becoming a resource by supporting research, funding projects such as training and knowledge building and information sharing activities, as well as "governance and management advice, information technology infrastructure, skill and leadership development and information” (Loza, 2004:304).

The partnership could also be a triadic system which would consist of government, community and a university. In this partnership, the university may act as a conduit or "intermediary" with government building capacity in communities via universities as knowledge holders (Kindred and Petrescu, 2015). In this partnership, universities are often funded by government in order to build capacity in communities. This triadic partnership may start with a call for proposals from government for organisations or institutions for the development and implementation of programmes to build capacity in communities.

These programmes are often developed to work towards strengthening families. However, the triadic partnership may also develop due to funding from government to communitybased organisations to add in a research component to the programmes they implement but these are very limited as the focus is often on programme implementation and reaching goals and target populations.

The important aspect of the partnership is that all participants have clear roles and responsibilities, and that these aspects are located in the contribution made to the 
partnership (Miller, Krusky, Franzen, Cochran and Zimmerman, 2012; Frabutt, Forsbrey and MacKinnon-Lewis, 2003).

For the purpose of this paper, the focus is on the dyadic system partnership between the university and the community to address the questions of what and how the parties contribute.

From a university perspective, the what of the contribution is seen in knowledge and skills production with the purpose of capacity development and evidence-based practice. According to Schütze (2010), this is achieved through knowledge transfer and continuing education. In the how, there are different processes that are used to implement the partnership. For example, Doherty and Mendenhall (2006) propose a citizen healthcare model which uses seven action strategies to implement the model by having the university approach members or community stakeholders to improve health in the community via a collaborative and empowerment process of engagement. These seven action strategies include "(1) Attainment of buy-in from key professional leaders and administrators; (2) The identification of a concerning health issue to both professionals and members of a specific community (clinic, neighbourhood, cultural group in a geographic location); (3) Identifying potential community leaders [stakeholders] who have personal experience with the health issue and who have relationships with the professional team; (4) Invite a small group of community leaders (three to four people) to meet several times with the professional team to explore the issue and see if there is a consensus to proceed with a larger community project; (5) This group decides how to invite a larger group of community leaders (10-15) to begin the process of generating the project; (6) The full planning group implements the community organising process; and (7) Employ key citizen healthcare processes (Democratic planning and decision making at every step, mutual teaching and learning among community members, creating ways to fold new learnings back into the community, identifying and developing leaders, using professional expertise selectively, forging a sense of larger purpose beyond helping immediate participants)" (Doherty and Mendenhall, 2006:256).

In a later publication, Doherty, Mendenhall and Berge (2010) stress the importance of community engagement to strengthen families using the Citizen Health Care Model, based on key principles, which they transposed into very simple language for community participants to understand. These are as follows:

- $\quad$ See all personal problems as public ones too.

- Look to family and community resources first.

- See families and communities as producers, not just as clients or consumers.

- See professionals as citizens and partners, not just as providers.

- Let citizens drive programs, rather than programs servicing citizens.

- Make sure every initiative reflects the local culture.

- Grow leaders, then more leaders.

- Make all decisions democratically. 
- Go deep before taking action.

- Think big, act practically and let your light shine.

More recently, Corbie-Smith, Adimora, Youmans, Muhammad, Blumenthal, Ellison and Lloyd (2011), use a staged approach which presents the initial processes and discussions to enter into and engage stakeholders in the community. This staged approach consists of four stages and include the following: Stage 1: Initial mobilisation; Stage 2: Establishing organisational structure; Stage 3: Capacity building for action; Stage 4: Planning for action. Quite a few studies employ community-based participatory research (CBPR) as an evidence-based approach using multiple partners to address complex problems (Belone, Lucero, Duran, Tafoya, Baker, Chan and Wallerstein, 2014; Kamando and Doyle, 2013; Bryan, 2009; Brody et al., 2004). Belone et al. (2014) highlight that in the CBPR, four dimensions are important if this approach is to be effective. These dimensions are context (ranging from health to social determinants), group dynamics (includes both structural and individual dynamics), intervention (translating and implementing) and outcomes (improvement, development and growth). A more common approach, which is similar to using an intervention mapping framework, is presented by Miller et al. (2012) as a fivestage approach to implement evidence-based programmes in communities. The five stages are: (1) a needs assessment, (2) adoption and adaptation, (3) capacity building and sustainability, (4) implementation and family engagement, and (5) programme evaluation. What is crucial in this approach, is that a thorough needs assessment is conducted taking into consideration an ecological approach to identify the needs of the family and the community as often the issue or concern is complex and, therefore, may required a multilevel intervention or approach. This needs assessment also uses a bottom-up perspective of the challenges in the community. The outcome of the needs assessment then results in the creation or development of goals for change, either in the behaviour of the person or in the environment. The needs and the goals are then closely aligned to the design of the program or intervention.

In the partnership, communities are also contributors to strengthening families and building communities. To address the question of what communities contribute, Horowitz, Robinson and Seifer, (2009) indicate that the community has knowledge, skills, attitudes, beliefs and practices because there is an authentic experience of the challenges presenting in the community. Furthermore, communities provide specific challenges related to geographical location, socio-economic status, history and culture (Schenck et al., 2010) which add to the complexities of the challenges in the community. The community provides the platform of learning for universities by providing learning opportunities for students (Allison, Khan, Reese, Dobias and Struna, 2015; Preece, 2013; Horowitz et al., 2009) that become a resource for universities. In addition, for communities, the how of partnership is located in the participatory nature of the partnership (Bryan, 2009). Communities have equal access, rights and responsibilities in the partnership (Preece, 2013; Miller et al., 2012; Bryan, 2009; Horowitz et al., 2009). 
The roles and responsibilities of the partners are important in the university-community partnership with creating, producing and sharing knowledge and skills; both must be actively engaged and present in the process geared towards social change (De Lange, Mnisi, Mitchell and Park, 2010). Furthermore, the partnership should be one of mutual respect as the community 'allows' access for universities and not only act as gate keepers, but become mutual participants and engagers in the partnership focusing on improving the well-being of families and communities. The universities respectfully engage with communities by safeguarding and protecting the history, culture and identity of the communities. This respectful engagement underlies the factors to consider in the sustainability of the partnership.

\section{Factors for a sustainable partnership}

According to O'Mara-Eves et al. (2013), motivation to participate in partnering varies for both universities and communities. These motivations could be personal, communal or societal. In their review of interventions, these authors found that the motivations of parties to participate would ultimately link to some form of benefit or gain which could include less crime, capacity-building, benefits for the community and neighbourhoods, improved education and so on.

In order for the university-community partnership to be successful, effective and sustainable, there are particular factors which are required. At a very basic level, the partnership should be constructed on the basis of mutual goals and expectations, the roles and responsibilities of parties, understanding the concerns and priorities of both parties, as well as resource-sharing, and capitalising on the strengths of each (Miller et al., 2012). This very basic level creates a sense of trust and being comfortable with power-sharing, thus creating room for future collaborations (Frabutt et al., 2003). University-community relationships can help close the gap between discovery and delivery and, in doing so, improve outcomes for under-resourced communities (Miller et al., 2012).

A study conducted by Ansari and Phillips (2001) explored the structural characteristics and operational issues which may either hinder or enhance the success and sustainability of a university-community partnership. In their explorations, certain factors were identified as: representation of community stakeholders, ownership of and commitment to the partnership, leadership, open communication, capacity-building, power issues and selfinterests, vision, clarity and transparency. Similarly, Miller et al. (2012) state that full commitment to the project from both parties is required, as well as open communication on the expectations of all partners for the effective translation of the project. Bryan (2009) believes that the partnership between universities and communities should be a democratic and collaborative process, that it should use empowerment strategies and create greater purpose and vision to strengthen and build families and communities.

Amey, Eddy and Ozaki (2007) believe that the partnership will be successful if the development of the partnership is developmental. They suggest that in order to evaluate the effectiveness and efficiency of the partnership, particular questions could be asked to 
assess if the goals of the partnership are being achieved. They suggest for example the following: Why and how was the partnership initiated? What were the motivations for each person's participation in the partnership? What are the outcomes, benefits and costs of the partnership? Is the communication effective and effective between partners in the partnership? What are the requirements for sustaining the partnership and how [resources] will this be done? There may be many more questions but these questions encourage a reflective process for a way forward to either enhance or revise the partnership in order to assess and maintain sustainability. This reflective process allows for flexibility to new inputs and adjustments.

Universities are in a unique position of generating and having the theoretical knowledge to explore real societal challenges (O'Mara-Eves et al., 2013; Preece, 2013). However, it is only understood and beneficial if it is applied as solutions to the real challenges. This is then not only beneficial for families and communities but it is also beneficial for universities as these applications become opportunities for interprofessional education and practice, improved teaching, learning opportunities for students as well as the potential development of scholarship (Van Dongen, Lenzen, Van Bokhoven, Daniëls, Van der Weijden and Beurskens, 2016). In addition in this declining financial support climate, if universities are addressing issues of concern to communities it may assist in improving the status of universities in terms of community status and awareness (Buys and Burnell, 2007).

\section{Conclusion}

Universities have a core mission or civic responsibility to assist in building and sustaining communities for the well-being of the people who live in communities such as families. This responsibility should, in practice, form a university-community partnership which is respectfully beneficial to both parties, with universities relinquishing a sense of power to empower communities and in this way creating a sharing power. The effective use of university-community partnerships is essential if we are to address the gaps between discovering ways to address the complex needs of society, and implementing the interventions discovered. Together, universities and communities can improve the needs of society if we understand that the partnership is an exchange of skills with mutual benefits to all parties, but it can only be effective if we understand and respect communities as having an own identity and being active participants in their own healing and well-being. Universities should then be flexible and adaptable in their processes of engagement. 


\section{References}

Allison, J., Khan, T.R., Reese, E., Dobias, B.S., and Struna, J. (2015). "Lessons from the Labor Organizing Community and Health Project: Meeting the Challenges of Student Engagement in Community-based Participatory Research" Journal of Public Scholarship in Higher Education 5:5-30.

Ansari, W.E. and Phillips, C.J. (2001). "Partnerships, Community Participation and Intersectoral Collaboration in South Africa” Journal of Interprofessional Care 15(2):119-132.

Amey, M.J., Eddy, P.L. and C.C. Ozaki (2007). "Demands for Partnership and Collaboration in Higher Education: A Model” New Directions for Community Colleges (139):5-14.

Belone, L., Lucero, J.E., Duran, B., Tafoya, G., Baker, E.A., Chan, D. and Wallerstein, N. Research Conceptual Model Community Partner Consultation and Face Validity" Qualitative Health Research 26(1):1-19.

Bryan, J. (2009). "Engaging Clients, Families, and Communities as Partners in Mental Health” Journal of Counseling and Development 87(4):507-511.

Buys, N. and Burnell, S. (2007). "Establishing University-community Partnerships: Processes and Benefits" Journal of Higher Education Policy and Management 29(1):73-86.

Corbie-Smith, G., Adimora, A.A., Youmans, S., Muhammad, M., Blumenthal, C., Ellison, A. and Lloyd, S.W. (2011). "Project GRACE: A Staged Approach to Development of a Community-Academic Partnership to Address HIV in Rural African American Communities" Health Promotion Practice 12(2):293-302.

De Lange, N., Mnisi, T., Mitchell, C., Park, E.G. (2010). "Giving Life to Data: UniversityCommunity Partnerships in Addressing HIV and AIDS through Building Digital Archives" Elearning and Digital Media 7(2):160-171.

Doherty, W.J. and Mendenhall, T.J. (2006). "Citizen Health Care: A Model for Engaging Patients, Families, and Communities as Coproducers of Health" Families, Systems and Health 24(3):251.

Doherty, W.J., Mendenhall, T.J. and Berge, J.M. (2006). "The Families and Democracy and Citizen Health Care Project" Journal of Marital and Family Therapy 36(4):389-402.

Frabutt, J.M., Forsbrey, A.D. and MacKinnon-Lewis, C. (2003). "A University-community partnership's use of Qualitative Methods to Foster Community Engagement in Adolescent Research” Journal of Higher Education Outreach and Engagement 8(2):105-118.

Higher Education Quality Committee South Africa (HEQC). (2004). Criteria for Institutional Audits Pretoria: Council of Higher Education. 
Horowitz, C.R., Robinson, M. and Seifer, S. (2009). "Community-based Participatory Research from the Margin to the Mainstream: Are Researchers Prepared?" Circulation 119(19):2633-2642.

Kamando, A. and Doyle, L. (2013). "Universities and Community-based Research in Developing Countries: Community Voice and Educational Provision in Rural Tanzania" Journal of Adult and Continuing Education 19(1):17-38.

Kindred, J., and Petrescu, C. (2015). "Expectations Versus Reality in a Universitycommunity Partnership: A Case Study” Voluntas 26:823-845.

Kirmayer, L.J., Sehdev, M., Whitley R., Dandeneau S.F., and Isaac, C. (2009). "Community Resilience: Models, Metaphors and Measures" International Journal of Indigenous Health 5(1):62-117.

Loza, J. (2004). "Business-Community Partnerships: The Case of Community Organization Capacity Building” Journal of Business Ethics 53:297-311.

Max-Neef, M.A. (1989). Human Scale Development: Conception, Application and Further Reflections New York: The Apex Press.

Miller, A.L., Krusky, A.M., Franzen, S., Cochran, S. and Zimmerman, M.A. (2012). "Partnering to Translate Evidence-based Programs to Community Settings: Bridging the Gap between Research and Practice" Health Promotion Practice 13(4):559-66.

O’Mara-Eves, A., Brunton, G., McDaid, G., Oliver, S., Kavanagh, J., Jamal, F., Matosevic, T., Harden, A. and Thomas, J. (2013). "Community Engagement to Reduce Inequalities in Health: A Systematic Review, Meta-analysis and Economic Analysis" Public Health Research 1(4):1-526.

Preece, J. (2013). "Towards an Africanisation of Community Engagement and Service Learning" Perspectives in Education 31(2):114-122.

Schenck, R., Nel, H. and Louw, H. (2010). Introduction to Participatory Community Practice Pretoria: Unisa Press.

Schütze, H.G. (2010). "The 'Third Mission' of Universities: Community Engagement and Service" in Inman, P. and Schütze, H.G. (Eds.). The Community Engagement and Service Mission of Universities Leicester: Niace, 13-31.

Steuart, G.W. (1993). "Social and Cultural Perspectives: Community Intervention and Mental Health" 1978 Health Education Quarterly S99. 
United Nations Educational, Scientific and Cultural Organization (UNESCO). (1998). "World Conference on Higher Education", http://http://unesdoc.unesco.org/images/ oo11/ o01163/116345e.pdf (Accessed on 26/05/16).

Van Dongen, J.J.J., Lenzen, S.A., Van Bokhoven, M.A., Daniëls, R., Van der Weijden, T. and Beurskens, A. (2016). "Interprofessional Collaboration Regarding Patients' Care Plans in Primary Care: A Focus Group Study into Influential Factors" BMC Family Practice 17(58):1-10.

Wilcox, D. (1994). The Guide to Effective Participation Brighton: Delta Press. 